This article has been accepted for publication in a future issue of the Cyberpsychology, Behavior, and Social Networking journal, but has not been fully edited. Content may change prior to final publication. Citation information: https://doi.org/10.1089/cyber.2018.0667

\title{
Cultural Correlates of Internet Addiction
}

Agata Błachnio, Aneta Przepiorka, Oleg Gorbaniuk, Martina Benvenuti, Adela Magdalena Ciobanu, Emre Senol-Durak, Mithat Durak, Michail N. Giannakos, Elvis Mazzoni, Ilias O. Pappas, Camelia Popa, Gwendolyn Seidman, Anise M.S. Wu, Shu Yu, and Menachem Ben-Ezra

\section{Abstract}

Increasing problems connected with excessive Internet use can be observed all over the world. Internet addiction is defined as excessive involvement in the Internet with negative consequences. The main aim of the study was to investigate economic indicators as correlates of Internet addiction. The study was conducted in nine countries. The number of participants amounted to a total of 3,279 Internet users (54\% were female), with a mean age of $M=25.14(S D=10.03)$. The authors used Young's Internet Addiction Test. Additionally, some social and economic indicators characterizing the countries were taken into consideration. We found that Internet addiction was positively related to economic well-being, social progress, and human development as well as negatively related to human well-being, health, safety, and security. The results of the study contribute to the international debate on Internet addiction.

Keywords:

Internet addiction, economic indicators, social indicators, cultural indicators, countries, wellbeing

Cite as: Błachnio, A., Przepiorka, A., Gorbaniuk, O., Benvenuti, M., Ciobanu, A.M., Senol Durak, E., Durak, M., Giannakos, M.N., Mazzoni, E., Pappas, I.O. and Popa, C., 2019. Cultural Correlates of Internet Addiction. Cyberpsychology, Behavior, and Social Networking, 22(4), pp.258-263. https://doi.org/10.1089/cyber.2018.0667 


\section{Introduction}

All over the world, the Internet has become an indispensable tool in almost every aspect of human life. This fact is linked with the increasing accessibility of the Internet and with the problematic use of this tool. Internet addiction is defined as an excessive preoccupation with the Internet which brings about negative conseqences, such as distress 1 . According to Block ${ }^{2}$, Interent addiction is a compulsive-impulsive spectrum disorder linked with computer use such as excessive use, withdrawal symptoms, tolerance, and negative repercussions. Young ${ }^{1}$ defined Internet addiction as an impulse-control disorder without intoxication. Its symptoms include preoccupation with the Internet, problems with controlling one's Internet use, low positive mood, excessive amount of time spent online, low performance at school or work, deteriorating physical health, jeopardized relationships with family or friends, and lying about one's Internet use.

There have been a number of studies showing the relations between Internet addiction and psychological traits ${ }^{5} 7^{8}$, including self-esteem ${ }^{8}$, social self-efficacy and locus of control ${ }^{9}$, shyness ${ }^{10}$, life satisfaction ${ }^{11}$, and loneliness ${ }^{7}$. In the literature there are several measures of Internet addiction, such as the Online Cognition Scale ${ }^{12}$, the InternetRelated Problem Scale ${ }^{13}$, or the Problematic Internet Use Questionnaire ${ }^{14}$. The growing number of articles reporting studies using the Internet Addiction Test ${ }^{3}$ shows that this test is immensely popular and widely used not only in English ${ }^{15}$ but also in other languages into which it has been translated: Polish ${ }^{1617}$, German ${ }^{18}$, Chinese ${ }^{19}$, Spanish ${ }^{20}$, French ${ }^{21}$, Arabic ${ }^{22}$, Portuguese ${ }^{23}$, Italian ${ }^{24}$, and Greek ${ }^{25}$.

Nevertheless, there is an evident lack of findings regarding how culture and economic indicators of countries can explain the level of Internet addiction. Previous findings suggest that culture should be considered in explaining this phenomenon ${ }^{26}{ }^{27}$. Some evidence indicates that the level of Internet addiction differs across countries ${ }^{8}$, especially between Eastern and Western civilizations ${ }^{28}$. For instance, several years ago it was found that the prevalence of Internet addiction in Poland was between 
$2 \%{ }^{17}$ and $9 \%{ }^{29}$, compared to approximately $12 \%$ in China ${ }^{30}$. Other studies show that the level of Internet addiction differsacross Asian countries. Mak et al. (2014) found a higher prevalence of problematic or addictive Internet use in the Philippines (51\%) and Japan (48\%) comparedto the lower level of Internet addiction in China: 17\% for problematic and $2 \%$ for addictive Internet use. They also found that about $32 \%$ of people in Hong Kongused the Internet in problematic waysTheir meta-analysis reveals the diversity of Internet addiction and shows how its prevalence depends on the region. The Middle East is characterized by a higher prevalence of Internet addiction (10.9\%) than Northern and Western Europe $(2.6 \%)^{28}$.

A meta-analyses revealed that countries with higher traffic time consumption, pollution, and dissatisfaction with life tend to score higher on Internet addiction ${ }^{28}$. The main aim of the present paper is to fill the gap in the understanding of the causes of these crossnational differences by investigating economic indicators as predictors of Internet addiction. We used several economic indicators, such as Internet penetration for each country ${ }^{[1]}$, Human Development Index (HDI) ${ }^{[2]}$, and Sustainable Society Index (SSI $)^{[3]}$ with three dimensions: human well-being, environmental well-being, and economic well-being ${ }^{[4]}$. Internet penetration is the percentage of users in a population who have Internet access. We also measured the Legatum Prosperity Index, which has eight aspects: economy, entrepreneurship \& opportunity, governance, education, health, safety \& security, personal freedom, and social capital. Moreover, we examined the dimensions of culture distinguished by Hofstede: individualism-collectivism, uncertainty avoidance, power distance, and masculinity-femininity ${ }^{[5]}$, as well as theSocial Progress Index (SPI) ${ }^{[6]}$ which includes three aspects: basic human needs, foundations of wellbeing, and opportunity. Finally, we took into account the World Happiness Index, ${ }^{[7]}$ published since 2012, presenting the state of global happiness and the ranks of countries according 
to their happiness level. We predicted that the level of Internet addiction would differ depending on these culture-level indicators. Next, we set out to examine gender differences within countries as well as the prevalence of Internet addiction in each country. Materials and Methods Participants and Procedure

The sample consisted of 3,279 participants from nine countries: China $(N=388$, $63 \%$ female), Greece $(N=253,40 \%$ female $)$, Israel $(N=286,81 \%$ female $)$, Italy $(N=317$, $67 \%$ female), Poland $(N=453,52 \%$ female), Romania $(N=273,46 \%$ female), Turkey ( $N=395,69 \%$ female), USA $(N=224,73 \%$ female $)$, and Ukraine $(N=341,66 \%$ female $)$. Their mean age was $M=25.14(S D=10.03)$, and 1,789 of the participants $(54.6 \%)$ were female.

The participants met one criterion: they were Internet users. They were informed about the anonymity of the research. Some of the results obtained -unrelated to the objective of the current study and concerning Facebook use - have been presented elsewhere ${ }^{32}$.

\section{Measures}

The participants from the nine countries completed an online survey measuring Internet addiction. The questionnaire was administered in the native language of each country.

Young's Internet Addiction Test (IAT) consists of 20 items (e.g., How often do you become defensive or secretive when anyone asks you what you do on-line?; How often do you block out disturbing thoughts about your life with soothing thoughts of the Internet?). The IAT is a valid cosmopolitan one-factor instrument for measuring Internet addiction. Each item is rated on the following Likert scale: $n o t$ applicable, rarely, occasionally, frequently, often, and always. Cronbach's $\alpha$ was .95 for Poland, .93 for Israel, .89 for China, .90 for Romania, .90 for Italy, .91 for the USA, .90 for Turkey, .95 for Greece, and .85 for Ukraine. 
As seen in Table 1, by all conventions, Tucker's phi indicated a good cross-cultural equivalence of the Internet Addiction Test ${ }^{33}$, but the results of the Italian sample showed somewhat lower congruence, although acceptable at the lowest threshold ${ }^{34}$.

\section{Statistical analyses}

Descriptive analyses are presented as means and standard deviations of IAT scores for each country. Gender differences in each country were measured bymeans of a $t$ test.

Cohen's $d$ was used as effect size measure. Effects sizes are defined as small $(d=0.2)$, medium $(d=0.5)$, and large $(d=0.8)^{35}$. One-way ANOVA and post hoc Dunnett's T3 test were used to determine the differences between countries. We used multilevel regression to test our hypotheses concerning country-level correlates; this procedure takes the hierarchical structure of the data into account and enables the accurate estimation of standard errors by decomposing the total variance into within-country variability and between-country variability ${ }^{36}$.

Results

The descriptive statistics (means and standard deviations of IAT scores for each country) are presented in Table 1 . Table 1 displays also the prevalence of Internet addiction in the studied countries. We used the cut-off points proposed by Kuss ${ }^{37}$, where severe problem users scored 70-100, frequent problem users scored 40-69, and normal users scored 0-39.

The mean level of Internet addiction for the whole sample was $M=27.76(S D=15.41)$. The results of gender difference testing (Cohen's $d$ effect size) for each country are also presented. In China $(d=0.21, p<.05)$, Italy $(d=0.33, p<.01)$, Turkey $(d=0.27, p<.05)$, and Greece $(d=0.52, p<.001)$, men scored higher than women in the IAT. In Israel, the level of Internet addiction was higher in women $(d=0.38, p<.01)$.

Table 1. Tucker's phi coefficients of IAT factor structure similarity in each country, gender and country difference testing and prevalence of Internet addiction in studied countries

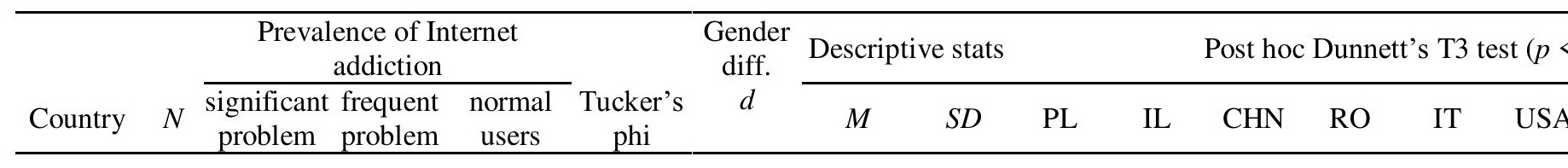




\begin{tabular}{lcccccccccccccc}
\hline Poland & 453 & 2.0 & 18.5 & 79.5 & .999 & 0.15 & 28.11 & 16.36 & & & & \\
Israel & 311 & 1 & 12.2 & 70.4 & .979 & $-0.38^{* *}$ & 24.82 & 15.08 & .164 & & & \\
China & 388 & 0 & 8.5 & 91.5 & .918 & $0.21^{*}$ & 22.23 & 11.57 & .001 & .409 & & \\
Romania & 273 & 0 & 8.4 & 91.6 & .927 & 0.03 & 22.37 & 12.75 & .001 & .729 & 1.000 & \\
Italy & 317 & 2.5 & 45.7 & 51.7 & .669 & $0.33^{* *}$ & 40.34 & 11.34 & .001 & .001 & .001 & .001 & \\
USA & 238 & 0.4 & 16.4 & 79.4 & .997 & 0.00 & 28.74 & 13.48 & 1.000 & .059 & .001 & .001 & .001 \\
Turkey & 395 & 0.5 & 10.4 & 89.1 & .928 & $0.27^{*}$ & 22.75 & 13.35 & .001 & .896 & 1.000 & 1.000 & .001 & .001 \\
Greece & 253 & 7.1 & 39.9 & 53.0 & .888 & $0.52^{* * *}$ & 38.42 & 20.28 & .001 & .001 & .001 & .001 & .999 & .001 \\
Ukraine & 341 & 0.6 & 10.6 & 85.9 & .980 & -0.13 & 26.22 & 12.03 & .900 & 1,001 & .001 & .005 & .001 & .548 \\
\hline${ }^{*} p<.05 ;{ }^{* *} p<.01 ;{ }^{* * *} p<.001 ;$ Cohen's $d-$ the standardised IAT difference between men and women & & &
\end{tabular}

One-way ANOVA on Internet addiction scores with country as an independent variable revealed statistically a significant

difference: $F(8,2890)=70.615, p<.001, \eta^{2}=.163$. A Dunnett T3 post hoc test revealed a number of significant differences in the prevalence of Internet addiction. Poland scored higher on IA than Israel, China, Romania, and Turkey and lower than Italy and Greece. Israel scored lower than Italy and Greece. China scored lower than Italy, the USA, Greece, and Ukraine. Romania scored lower than Italy, the USA, Greece, and Ukraine. Italy scored higher than the USA, Turkey, and Ukraine. The USA scored higher than Turkey and lower than Greece. Turkey scored lower than Greece and Ukraine, and Greece scored higher than Ukraine.

Table 2. The multilevel linear regression of Internet addiction on some economic and cultural indices of the countries

\begin{tabular}{lccc}
\hline \multicolumn{1}{c}{ Indices } & $\beta$ & $b$ & $p$ \\
\hline Internet Penetration & 0.016 & 0.222 & 0.217 \\
Human Development Index & 0.575 & 56.446 & 0.018 \\
\multicolumn{1}{c}{ Sustainable Society Index } & & & \\
Human Well-Being & - & -0.255 & 0.001 \\
Environmental Well-Being & 0.575 & & \\
Economic Well-Being & 0.005 & 0.107 & 0.635 \\
& 0.569 & 0.103 & 0.001 \\
Econotum Prosperity Index & & & \\
Entrepreneurship \& Opportunity & 0.112 & 0.017 & 0.679 \\
Governance & - & -0.070 & 0.394 \\
Education & 0.150 & & \\
& - & -0.046 & 0.109 \\
& 0.211 & & \\
& - & -0.053 & 0.554
\end{tabular}




\begin{tabular}{lccc} 
Health & - & -0.126 & 0.045 \\
Safety \& Security & 0.457 & & \\
& - & -0.010 & 0.024 \\
Personal Freedom & 0.435 & & \\
& - & -0.029 & 0.555 \\
Social Capital & 0.169 & & \\
& - & -0.004 & 0.952 \\
& 0.020 & & \\
Social Progress Index & & & \\
World Happiness Index & 0.504 & 0.391 & 0.043 \\
& 0.004 & 0.028 & 0.985 \\
The dimensions of culture & & & \\
Power distance & - & -0.072 & 0.350 \\
Individualism & 0.269 & & \\
Masculinity & 0.450 & 0.125 & 0.113 \\
Uncertainty avoidance & 0.469 & 0.225 & 0.104 \\
& 0.236 & 0.067 & 0.277 \\
\hline
\end{tabular}

In order to answer the question of which economic, social, and cultural indicators of the countries (between-level variables) correlate with Internet addiction (individual-level variable), we computed two-level regression for each of the indicators separately (see Table 2). The ICC (intraclass correlation) of the IAT was .169, which justified the use of multilevel analysis. The results of analyses show that Internet addiction is higher when the indicators of Human Well-Being $(p<.001)$, Safety \& Security $(p<.05)$, and Health $(p<.05)$ are lower and when Economic Well-Being $(p<.001)$, the Human Development Index $(p<.05)$, and the Social Progress Index $(p<.05)$ are higher.

Table 3. 2-level multiple regression analysis of Internet addiction on significant economic and cultural indices

\begin{tabular}{lccc}
\hline & $b$ & $S E(b)$ & $p$ \\
\hline Human Well-Being & -0.636 & 0.250 & 0.011 \\
Economic Well-Being & 0.016 & 0.041 & 0.697 \\
Human Development Index & -17.995 & 48.647 & 0.711 \\
Safety \& Security & 0.108 & 0.076 & 0.152 \\
Health & -0.419 & 0.162 & 0.010 \\
Social Progress Index & 0.795 & 0.237 & 0.001 \\
Intercepts & 137.799 & 53.072 & 0.009 \\
\hline
\end{tabular}

Next, we performed a two-level multiple regression analysis (see Table 3), in which we entered variables significantly correlated with IA (within-country level) as countrylevel explanatory variables (see Table 4). Due to the intercorrelation of IA indicators in the model, only three of them turned out to be statistically significant: the positively 
correlated Social Progress Index $(p<.05)$ as well as the negatively correlated Health $(p<.05)$ and Human Well-Being $(p<.001)$. In the literature it is also possible to find suggestions that there are gender differences regarding the aspects of the Internet that men and women are addicted to ${ }^{43}$. Our results are in line with those of previous studies, but not in all countries. Both our results and previous ones suggest that gender differences may depend on culture.

The prevalence of Internet addiction in the studied countries ranges from 0 (in China and Romania) to 7.1 (in Greece). The reasons can be many. First, this may point to cultural differences, but on the other hand it may stem from the fact that in some cultures there is a mechanism of denying, or refusing to admit to, excessive Internet use. Attempts to determine the level of Internet addiction problems often encounter reactions of shame or minimization ${ }^{44}$. It should also be remembered that denying addiction and losing control over the amount of time spent online are among the main symptoms of addiction ${ }^{3}$, and perhaps in some cultures this denial mechanism is stronger than in others. Second, the measurement of Internet addiction is difficult due to comorbidity ${ }^{2}$. Patients diagnosed with Internet addiction are often also diagnosed with a different disorder listed in DSM-5. Third, there are no reliable data that our results regarding the level of Internet addiction in particular countries could be compared to. One of the reasons for this diversity of results may be differences in sample sizes and non-representative methods of data collection (online vs. offline).

\section{Limitations}

The present study is limited by the self-report method of assessment. Additionally, the study was cross-sectional in nature, which means we cannot conclude about causal relationships. Another limitation is that the selected countries included in the study may not accurately represent their regions. Similarly, the participants in each country were not randomly sampled and thus may not be representative of all citizens. Moreover, the relatively small numer of countries included in the study does not make it possible to identify weaker relationships between country-level variables and within-level variables. In future studies, more countries should be examined. In the present study, only non-clinical Internet 
users were included in the samples, and therefore a replication of the study with a clinical population may be a good direction for future research.

\section{Conclusions}

One of the issues examined in the presented research is the relationships between IA and socioeconomic factors. The results seem to confirm the findings of earlier studies, conducted at the individual level. Hard socioeconomic indicators are often identical with the variables that were measured at the individual level in previous studies. The study adds to the body of research on the relationship between national culture and individual behavior. We conclude that not only personality traits but also the cultural and economic characteristics of the countries where users live can explain the Internet addiction phenomenon. Further studies should be conducted for a deeper understanding of the cultural and economic determinants of Internet addiction. This study makes an important contribution to the current knowledge about Internet addiction by demonstrating the varied nature of its determinants.

\section{References}

1. Stavropoulos V, Kuss D, Griffiths M, Motti-Stefanidi F. A Longitudinal Study of Adolescent Internet Addiction: The Role of Conscientiousness and Classroom Hostility. Journal of Adolescent Research. 2015;31:442-473. doi:10.1177/0743558415580163.

2. Block JJ. Issues for DSM-V: internet addiction. American Journal of Psychiatry. $2008 ;: 306-307$.

3. Young KS. Internet Addiction : Symptoms, Evaluation, And Treatment. 1999;17.

4. Pezoa-Jares RE. Internet Addiction: A Review. Journal of Addiction Research \& Therapy. 2012. doi:10.4172/2155-6105.S6-004. 
5. Yang L, Sun L, Zhang Z, Sun Y, Wu H, Ye D. Internet addiction, adolescent depression, and the mediating role of life events: finding from a sample of Chinese adolescents. International Journal Of Psychology: Journal International De Psychologie. 2014;49:342-347. doi:10.1002/ijop.12063.

6. Scimeca G, Bruno A, Cava L, Pandolfo G, Muscatello MRA, Zoccali R. The Relationship between Alexithymia, Anxiety, Depression, and Internet Addiction Severity in a Sample of Italian High School Students. TheScientificWorldJournal. 2014;2014. doi:10.1155/2014/504376.

7. Bozoglan B, Demirer V, Sahin I. Loneliness, self-esteem, and life satisfaction as predictors of Internet addiction: A cross-sectional study among Turkish university students. Scandinavian Journal of Psychology. 2013;54:313-319. doi:10.1111/sjop.12049.

8. Błachnio A, Przepiórka A, Senol-Durak E, Durak M, Sherstyuk L. The role of self-esteem in Internet addiction: a comparison between Turkish, Polish and Ukrainian samples. The European Journal of Psychiatry. 2016;30:149-155.

9. İskender M, Akin A. Social self-efficacy, academic locus of control, and internet addiction. Computers \& Education. 2010;54:1101-1106. Available at: 10.1016/j.compedu.2009.10.014.

10. Chak K, Leung L. Addiction and Internet Use. Cyberpsychology \& Behavior. 2004;7.

11. Lachmann B, Sariyska R, Kannen C, Cooper A, Montag C. Life satisfaction and problematic Internet use: Evidence for gender specific effects. Psychiatry research. 2016;238:363-367.

12. Davis R a, Flett GL, Besser A. Validation of a New Scale for Measuring Problematic Internet Use: Implications for Pre-employment Screening. CyberPsychology \& Behavior. 2002;5:331-345. doi:10.1089/109493102760275581. 
13. Armstrong L, Phillips JG, Saling LL. Potential determinants of heavier Internet usage. International Journal of Human-Computer Studies. 2000;53:537-550.

14. Demetrovics Z, Szeredi B, Rózsa S. The three-factor model of Internet addiction: The development of the Problematic Internet Use Questionnaire. Behavior Research Methods. 2008;40:563-574. doi:10.3758/BRM.40.2.563.

15. Widyanto L, McMurran M. The psychometric properties of the internet addiction test. Cyberpsychology \& behavior. 2004;7:443-50. doi:10.1089/cpb.2004.7.443.

16. Hawi NS, Blachnio A, Przepiorka A. Polish validation of the Internet Addiction Test. Computers in Human Behavior. 2015;48:548-553. doi:10.1016/j.chb.2015.01.058.

17. Poprawa R. Test problematycznego używania Internetu. Adaptacja i ocena psychometryczna Internet Addiction Test K. Young. Przeglad Psychologiczny. 2011;54:193-216.

18. Barke A, Nyenhuis N, Kröner-Herwig B. The German version of the internet addiction test: a validation study. Cyberpsychology, behavior and social networking. 2012;15:534-42. doi:10.1089/cyber.2011.0616.

19. Chang MK, Law SPM. Factor structure for Young's Internet Addiction Test: A confirmatory study. Computers in Human Behavior. 2008;24:2597-2619.

20. Fernandez-Villa T, Molina AJ, Garcia-Martin M, Llorca J, Delgado-Rodriguez M, Martin V. Validation and psychometric analysis of the Internet Addiction Test in Spanish among college students. BMC Public Health. 2015;15:953. doi:10.1186/s12889-0152281-5.

21. Khazaal Y, Billieux J, Thorens G, et al. French Validation of the Internet Addiction Test. 2008;11. doi:10.1089/cpb.2007.0249. 
22. Hawi NS. Arabic validation of the Internet addiction test. Cyberpsychology, behavior and social networking. 2013;16:200-4. doi:10.1089/cyber.2012.0426.

23. Pontes HM, Patrão IM, Griffiths MD. Portuguese validation of the Internet Addiction Test: An empirical study. Journal of Behavioral Addictions. 2014;3:107-114. doi:10.1556/JBA.3.2014.2.4.

24. Faraci P, Craparo G, Messina R, Severino S. Internet Addiction Test (IAT): Which is the best factorial solution? Journal of Medical Internet Research. 2013;15:1-11. doi:10.2196/jmir.2935.

25. Tsimtsiou Z, Haidich AB, Kokkali S, Dardavesis T, Young KS, Arvanitidou M. Greek version of the Internet Addiction Test: A validation study. Psychiatric Quarterly. 2014;85:187-195. doi:10.1007/s11126-013-9282-2.

26. Błachnio A, Przepiorka A, Senol-Durak E, Durak M, Sherstyuk L. The role of personality traits in Facebook and Internet addictions: A study on Polish, Turkish, and Ukrainian samples. Computers in Human Behavior. 2017;68:269-275. doi:10.1016/j.chb.2016.11.037.

27. Chen L, Nath R. Understanding the underlying factors of Internet addiction across cultures: A comparison study. Electronic Commerce Research and Applications. 2016;17:38-48.

28. Cheng C, Li AY-L. Internet Addiction Prevalence and Quality of (Real) Life: A MetaAnalysis of 31 Nations Across Seven World Regions. Cyberpsychology, Behavior, and Social Networking. 2014;17:755-760. doi:10.1089/cyber.2014.0317.

29. Kirwil L. Polskie dzieci w Internecie . Zagrożenia i bezpieczeństwo na tle danych dla UE. Wstępny raport z badań EU Kids Online przeprowadzonych wśród dzieci w wieku 916 lat i ich rodziców. Warszawa: Szkoła Wyższa Psychologii Społecznej Warszawa. 2010. 
30. Jiang Q, Leung L. Effects of individual differences, awareness-knowledge, and acceptance of Internet addiction as a health risk on willingness to change Internet habits. Social Science Computer Review. 2012;30:170-183.

31. Mak K-K, Lai C-M, Watanabe H, et al. Epidemiology of Internet Behaviors and Addiction Among Adolescents in Six Asian Countries. Cyberpsychology, behavior and social networking. 2014;17:720-728. doi:10.1089/cyber.2014.0139.

32. Błachnio A, Przepiorka A, Benvenuti M, et al. Cultural and Personality Predictors of Facebook Intrusion: A Cross-Cultural Study. Frontiers in Psychology. 2016;7:1895. doi:10.3389/fpsyg.2016.01895.

33. Lorenzo-Seva U, Berge JMF. Tucker' s Congruence Coefficient as a Meaningful Index of Factor Similarity. 2006;2:57-64. doi:10.1027/1614-1881.2.2.57.

34. Tucker LR. (1951) A method for synthesis of factor analysis studies. Educational Testing Service Princeton $\mathrm{Nj}$

35. Cohen J. Statistical power analysis for the behavioural sciences. 1988.

36. Raudenbush SW, Bryk AS. (2002) Hierarchical linear models: Applications and data analysis methods. Sage

37. Kuss DJ, Griffiths MD, Karila L, Billieux J. Internet addiction: a systematic review of epidemiological research for the last decade. Current Pharmaceutical Design. 2014;20:4026-4052.

38. Wu C-Y, Lee M-B, Liao S-C, Chang L-R. Risk Factors of Internet Addiction among Internet Users: An Online Questionnaire Survey. Plos One. 2015;10:e0137506. doi:10.1371/journal.pone.0137506.

39. Canan F, Ataoglu A, Ozcetin A, Icmeli C. The association between Internet addiction and dissociation among Turkish college students. Comprehensive psychiatry. 2012;53:422426. 
40. Poli R, Agrimi E. Internet addiction disorder: prevalence in an Italian student population. Nordic journal of psychiatry. 2012;66:55-59.

41. Liu TC, Desai RA, Krishnan-Sarin S, Cavallo DA, Potenza MN. Problematic Internet Use and Health in Adolescents. The Journal of Clinical Psychiatry. 2011;72:836-845. doi:10.4088/JCP.10m06057.

42. Ferraro G, Caci B, D’Amico A, Di Blasi M. Internet addiction disorder: an Italian study. Cyberpsychology \& behavior : the impact of the Internet, multimedia and virtual reality on behavior and society. 2007;10:170-5. doi:10.1089/cpb.2006.9972.

43. Chiu S-I, Hong F-Y, Chiu S-L. An Analysis on the Correlation and Gender Difference between College Students' Internet Addiction and Mobile Phone Addiction in Taiwan. ISRN Addiction. 2013;2013. doi:10.1155/2013/360607.

44. Beard KW, Wolf EM. Modification in the proposed diagnostic criteria for Internet addiction. Cyberpsychology \& behavior. 2001;4:377-383.

[1] http://www.internetlivestats.com/internet-users-by-country/

${ }^{[2]} \mathrm{http} / / / \mathrm{hdr}$.undp.org/en/content/human-development-index-hdi

${ }^{[3]}$ http://www.ssfindex.com/

${ }^{[4]}$ http://www.ssfindex.com/

${ }^{[s]}$ https://geert-hofstede.com/

${ }^{[6]} \mathrm{http}: / / \mathrm{www}$.socialprogressimperative.org/global-index/

${ }^{[7]} \mathrm{http}: / /$ worldhappiness.report/

${ }^{[8]} \mathrm{http}: / /$ worldhappiness.report/ 